\title{
RESTRIÇÕES À HIPÓTESE DO CONHECIMENTO MÚTUO NO PROCESSO COMUNICATIVO
}

\author{
Jane R.C. da Silveira
}

\section{Consideraçôes preliminares}

A teoria da relevancia, desenvolvida na obra Relevance: Communication and Cognition de Sperber-Wilson (S-W) (1986), por suas propriedades especulativas e cognitivas e por tratar ou adimitir o fenômeno da comunicaçăo humana como caracterizado também pela vaguidade e nà̊ apenas pelo compromusso da informaçâo precisa, conforme os modelos tradicionais (modelos correlacionais de código), tem recebido criticas de diversos estudiosos que se ocupam dessa área

O objetivo deste artigo é destacar uma dessas questôes polêmicas, especificamente a que se refere à rejeicão, por 5-W, da hipótese do conhecimento mûtuo $(\mathrm{CM})$, a qual é substituida pela noçảo de ambientes cognitivos mutuamente manisfestos. Tal noçào é um pressuposto fundamental da teoria e, consequèentemente, do principio da relevància (PR), e será discutida com base em argumentos que possibihtem esclarecer o verdadeirc propósito dos autores.

O critério pragmático proposto por S-W parte de uma concepcà̃o básica sobre a cognição humana, a de que esta é orientada para ou dirigida pela relevăncia no processo comunicacional, ou seja, a concepçáo de que prestamos atençảo apenas em informaçôes que nos parecem relevantes. S-W (1991:544) enfatizam que o PR náo é algo que deva ser conhecido, aprendido ou obedecido no comportamento comunicativo; a relevância, entâo, é tratada como sendo inerente ao processo de compreensáo humana.

Este estudo está dividido em très seçóes: (1) a apresentaçáo do quadro teórico, caracterizando resumidamente a teoria e o PR; (ii) a formulaçáo, discussão e análise das criticas feitas por Clark e Gerrig à posiçẫo teórica de S-W quanto à noção de $\mathrm{CM}$ : e (uii) a conclusăo das questóes discutidas e analisadas, destacando a pertinència dos argumentos dos autores de 'Relevance', no seu modelo de comunicaçào ostensiva-inferencial, apresentado como uma alternativa de aprimoramento aos modelos inferenciais adotados

\begin{tabular}{|l|l|l|l|l|l|}
\hline R. FAMLCOS & Porto Alege & n.3 & p.21-39 & setembro 1995 & semestral \\
\hline
\end{tabular}


por pragmaticistas de tradiçào griceana.

\section{2- Quadro teórico}

Partindo de Grice (1975), que delineou uma alternativa inferencial para o modelo de código, sugerindo um método em que as hipóteses pragmáticas poderiam ser confirmadas ou desconfirmadas através do Principio Cooperativo e da obediência às suas máximas conversacionais, $5 . W$, em seu estudo sobre a relevància, embora reconheçam os méritos da teoria griceana como essencial para descrever a natureza da inferéncia ou implicatura pragmática na comunicaçao verbal, interpretam cognitivamente esse modelo, ampliando a sua capacidade descritiva e explanatónia.

Diferentemente de Grice e dos pragmaticistas que seguem sua linha teórica, os autores năo consideram que qualquer aspecto da interpretaçăo do enunciado pragmaticamente determinado é sempre uma implicatura, com exceção da desambiguaçào e da atribuição do referente Para eles, a combinaçấo de caracteristicas conceituais contextualmente inferidas $e$ lingüisticamente decodificadas constitui a explicatura, que é uma suposiçióo explicitamente comunicada, e argumentam que todas as explicaturas do enunciado podem ser inferidas do contexto, da forma proposicional do enunciado e da atitude proposicional expressa pelo falante

S-W centram o enfoque da relevância no fato de que o hiato existente entre as representaçôes semainticas das sentencas e os pensamentos realmente comunicados pelos enunciados deve ser preenchido naio pela codificação, mas por inferências; vinculam, assim, a linguagem à cogniçảo humana $e$ nà̀ ao código. Entendem que pensamentos sào representaçóes conceituais (opostas a representaçôes sensórias ou a estados emocionais) e que as suposiçóes sảo os pensamentos do individuo tratados como representaçoes do mundo real.

Embora reconhecam as intençóes do comunicador como desempenhando um papel fundamental na compreensado, salientam que at comunicagào intencional humana nunca é um mero processo de codificacăo e decodificaçao. Isso porque as representaçoes semânticas codificadas linguisticamente săo estruturas mentais abstratas que devem ser inferencialmente enriquecidas com base na intencào informativa do falante antes de serem tomadas como representando qualquer coisa de interesse a ser comunicada. Um estimulo lingoístico, ao acionar um processo automático de decodificaçâo, leva-nos a recuperar a sua representaço semântica. 0 sistema de decodificaçào linguística possui as caraceristicas dos sistemas perceptuats, reflexos e automáticos e, de acordo com Fodor (1983), trata-se de um sistema de input, e nầo de processamento central, nẫo devendo ser considerado como parte da compreensaio, mas como algo que simplesmente fornece um estimulo para esse processo

Para S-W, a comunicaçấo verbal propriamente dita ocorre quando se reconhece que o falante está dizendo algo a alguêm, e o objetivo da 
pragmática é explicar como a tarefa do ouvinte, essencialmente inferencial, pode ser realizada para a compreensaio. Entendendo que a verdadeira intençào comunicativa é a intençáo de ter uma intençấo informativa reconhecida, os autores sugerem um critério explicito para chegar as hipóteses sobre a intençăo do comunicador: os seres humanos prestam atença ao mais relevante fenômeno disponivel. Tendem a construir a representaçäo mais relevante possivel deste fenòmeno e a processá-la num contexto que maximiza sua relevância

Mas quais sào as formas de inferễncia realizadas pelo ouvinte na compreensâo verbal? E como a informaçăo é mentalmente representada e inferencialmente processada? Para os autores, na compreensáo de enunciados, em que o raciocinio dedutivo desempenha um papel fundamental, as inferências sâo nâo-demonstrativas, derivadas de um cálculo năotrivial. Ou seja, nẫo há, necessariamente, regras que, dado um conjunto de premissas, gerem apenas um conjunto de conclusôes válidas. $O$ que ocorre é um processo de formaçáo e de confirmaçāo de hipóteses, a formaçào consistindo num processo criativo, de raciocínio analógico, de associagào de idéias, enquanto a confirmaçào de hipóteses vai depender do quanto elas se ajustam a dominios conexos de conhecimento e à concepçào global de mundo do individuo. Esses processos sio dedutivos globais, uma vez que tem livre acesso à informaçato contextual, nào partindo somente de premissas foxadas

O dominio por excelència de processos de inferências náodemonstrativas espontâneas săo as suposiçōes factuais, suposiçốes básicas mantidas como descriçóes verdadeiras do mundo, mas nāo sempre explicitamente representadas como verdadeiras, Quando adquiridas, são combinadas com um estoque de suposiçóes existentes, submetendo-se ac processo de inferência, cujo objetivo é modificar e aperfeiçoar a representaçấo de mundo do individuo.

Os processos de inferéncia usados na compreensio e comunicaçăo 4verbal do dia-a-dia são, na maioria dás vezes, espontâneos e essencialmente inconscientes, S-W sustentam que a formaçào de suposiçōes por deduçào é o processo-chave em inferência nảo-demonstrativa e que o processo de formaçấo e confirmaçăo de hipóteses é explicado pelo PR.

Este principio está articulado a conceitos importantes que constituem a base para que seja compreendido em toda a sua extensåo, A relevância é tratada pelos autores como uma relaçấo entre uma proposiçáo Pe um conjunto de suposiçóes contextuais $\mathrm{C}$, ou seja, uma informaçäo torna-se relevante para o individuo se ela interage com as suas suposiçōes anteriores sobre o mundo. A relevância, entào, é alcançada quando a adiçâo de uma proposiçắo a um contexto leva a uma modificaçāo do mesmo. Essa modificaçáo é chamada de efeitos contextuais, 05 quais podem ocorrer de tres maneiras: (a) combinando a informaçio nowa com o contexto prévio para fornecer 
implicaşóes contextuais) (b) fortalecendo (ou enfraquecendo) suposiçōes existentes; $e$ (c) contradizendo e eliminando suposiçoes anteriores.

Assim, uma implicação contextual nâo pode derivar de P ou de C sozinhos; ela é a contextualizaçăo de $\mathrm{P}$ em $\mathrm{C}$, e, quanto mais alto o valor de qualquer implicaçào contextual, maior a modificaçào do contexto. Mas,enquanto algumas inferências fortalecem suposiçóes já existentes. fornecendo maior evidência a elas, fenômeno chamado de força das suposiçóes, outras resultam numa contradição, levando o ouvinte a eliminar o que para ele é contraditório, isto ế, quando a nova e a velha informaçăo contradizem uma à outra, a mais fraca das duas suposiçóes é abandonada. A força das suposiçóes que fazemos no dia-a-dia pode vir de quatro fontes: (i) da percepçào, através de um estímulo sensório; (ii) da decodificaçăo lingüistica, por meio dos mecanismos de input linguístico; (iii) das suposiçóes ou esquemas de suposiçôes estocados na memória, que podem ser completados por informação contextual; e (iv) das deduçōes, que derivam suposiçōes adicionais como conclusóes de um processo dedutivo.

Segundo S-W, a forga das suposiçôes é comparável à sua acessibilidade: uma suposição é mais acessivel quanto mais facilmente lembrada ou processada. Por exemplo, num certo contexto, a suposiçio 0 nome da capital do RS é Porto Alegre' é mais acessivel que Porto Alegre chamava-se Săo francisco do Porto dos Casais em 1772'. Assim, quanto mais representada uma suposiçâ, maior a sua acessibilidade.

Os efeitos contextuais sầ, entäo, essenciais para o processo de compreensão e para a caracterização da relevância, descrita como uma propriedade importante da cogniçào humana. Para os autores, uma suposiçáo E relevante num contexto, se e somente se tem efeitos contextuais naquele contexto, mas devem ser considerados, também, os graus de relevância enquanto um conceito comparativo (e năo quantitativo), Argumentam que o processamento humano de informação requer algum esforço de atençào, memória e raciocínio, à medida que algum éfeito é alcancado em termos de alteraçó̀es das crenças do individuo: a adiçâo de novas crenças, o cancelamento das velhas ou simplesmente a mudança no grau de confiança em velhas crencas.

S-W sugerem que o cálculo de relevåncia é uma questâo de estimativa entre efeito contextual e esforço de processamento, fazendo uma analogia com a relaçâo 'custo-beneficio'. Afirmam que urma suposiçăo é relevante num contexto se os efeitos contextuais saio amplos $e$ o esforço requerido para processí-los é pequeno, de tal maneira que, quanto maiores os efeitos contextuais e quanto menor o esforço de processamento, maior a relevancia.

Às vezes, entretanto, mais esforço de processamento é compensado na relação com os efeitos alcançados. Assim, se A pergunta a B: Susana bebe uisque? e B responde: Ela nấo bebéáloool, a suposição uisque é alcoólico 
seria implicada e levaria a algumas implicaçōes contextuais que compensariam o esforsco extra de processamento por B nâo responder explicitamente Susana nảo bebe uisque, evitaria, por exemplo, que A oferecesse a Susana qualquer outra bebida alcoólica, levando A a concluir, por deduçâo, que Susana prefere bebidas leves.

Efeitos contextuais e esforço de processamento existem independentemente de cálculo consciente ou de serem representados conceitualmente e, quando o săo, é na forma de julgamentos intuitivos (comparativos). Na abordagem de S-W, a seleça de um contexto no processo da comunicaçalo é afetada pelos objetrvos de minimizar esforço de processamento e maximizar cleitos contextuais. A escolha de um contexto particular entre uma variedade de possiveis contextos para a interpretaçáo de um enunciado é guada pela busca da relevîncia; o contexto é restringido pela organizaçào da memória enciclopédica (conhecimento de mundo) de um individuo, pelas suas habilidades perceptuais e outras habilidades cognitivas e pela atividade mental na qual está engajado. A relevância, entâo, é dada, e o contexto, uma questấo de escolha, é uma variável. Desse modo, argumentam contra a abordagem que identifica o CM como o fator principal na compreensăo, por ele restringir o contexto a crencas e suposiçóes que devem ser compartilhadas enquanto mutuamente conhecidas pelo falante $e$ ouvinte.

5.W ressaltam que a sucessão de pensamentos de um individuo é guiada pela relevância máxima, que é alcançada com a seleçâo do melhor contexto possivel (equilibrando efeito e esforço de processamento) para a suposiçăo ses otimamente processada. Caracterizam também a relevância como uma propriedade de fenômenos (estimulos) que afetam o ambiente cognitivo de um individuo - o conjunto de todos os fatos que sào manifestos a ele, levando à construção de suposiçóes

Um estimulo é um fenòmeno usado para alcançar efeitos cognitivos; tomando uma intençáo informativa mutuamente manifesta. Por acreditarem que as pessoas nâo compartilham ambientes cognitivos totais, S-W aprimoram a noçào de CM, empiricamente inadequada, e a de informaçâo compartilhada. conceitualmente vaga, introduzindo a noçâo de manifestabilidade mútua. A manifestabilidade mútua $\hat{e}$ relativa a todas as suposiçôes manifestas num ambiente cognitivo mútuo, o qual significa qualquer ambiente compartilhado em que $e ́$ manifesto que as pessoas o compartilham sem a necessidade de ter as mesmas suposiçóes (embora sejam capazes disso). Constitui, entăo, uma manifestaçào potencial - perceptivel ou inferivel - mais fraca, menos exigente do que a de CM e mais compativel com a compreensaio verbal.

Segundo os autores, um estimulo pode tomar os fatos manifestos ou mais manifestos, mas um fato pode ser manifesto sem ser conhecido e suposto, pois o individuo nâo constrói todas as suposiçòes que o fenômeno torna 
manifestas. Algumas náo se pode deixar de fazer, por exemplo, as estimuladas por sons muito altos, claróes de luz, acenos de máo, ligadas a percepçóes auditivas, visuais e táteis, respectivamente. Os fenômenos menos favoráveis de serem relevantes são filtrados automaticamente, enquanto os mais favord́veis pré-esvaziam a atençào (os pais ouvindo o choro do seu bebê, por exemplo), Os enunciados lingúisticos, do mesmo modo que os estímulos năocodificados, a menos que sejam tratados como estímulos ostensivos, serăo simples ruidos ou marcas no papel.

O comportamento que toma manifesta a intençaio de tornar aigo manifesto, o estímulo ostensivo, além de atrair a atençăo da audiência e de estar focalizado na intençảo do comunicador, deve também revelar essa intençăodeve vir com garantia de relevância.

Um ato de ostensào é, entẫo, um requisito para a atenção, e esta, um requisito para a comunicaçào ostensiva-inferencial, a qual comunica uma presunçáo (inferência) de relevância ótima. A presunçâo de relevância é determinada por dois fatores: o esforço para processá-la otimamente, nunca maior que o requerido, e os efeitos alcançados por esse processamento b́timo, nunca menores que o necessário para tornar o estímulo válido de ser processado pelo ouvinte.

Assim, o PR é formulado por S-W (1986:161) como 'todo ato de comunicaçåo ostensiva comunica a presunção de sua relevância ótima", e tem o propósito de explicar a comunicaçăo inferencial como um todo, explícito e implícito, constituindo uma generalizaça. É aplicado sem exceçào: comunicador e destinatário náo seguem o PR, do modo como os falantes o fazem em relaçăo às máximas de Grice e năo poderiam violá-lo, mesmo se o quisessem, pois ele está presente em todo ato de comunicação ostensiva.

A tarefa do ouvinte - construir possiveis hipóteses interpretativas de um conjunto de suposiçōes - é efetivada, entâo, através do PR, que garante a seleçâo da primeira interpretaçăo acessivel ao destinatário, consistente com tal principio, S-W enfatizam que, para ser consistente com o PR, uma interpretaçăo não tem que ser otimamente relevante para o destinatário; simplesmente precisa ter parecido assim ao comunicador:

Embora nesse modelo de comunicacaio ostensiva-inferencial, centrado no PR, torne-se claro o papel do comunicador, envolvido com a ostensắo, e o do destinatário, envolvido com a inferência, os autores têm sidọ, algumas vezes, criticados ou mal interpretados em aspectos do seu quadro teórico. E disso que trataremos a seguir.

3- Formulação dos problemas, discussão e análise: conhecimento mútuo e ambientes cognitivos mutuamente manifestos.

Apresentados os fundamentos teóricos da relevãncia, passemos à análise e discussão dos problemas levantados por Clark (1987) e por Gerrig 
\{1987), quanto aos pressupostos de manifestabilidade mútua e ambiente cognitivo na teoria de S-W

Clark, ao questionar para qual propósito é relevante um ato comunicativo, afirma que S-W nầo explicitam isso em seu estudo. Argumenta que, na abordagem de intençóes informativas e comunicativas e de comunicaçào ostensiva-inferencial, os autores parecem seguir o insight de Grice(1975) e Austin (1962), segundo o qual a comunicachio humana deve ser tratada como parte de uma teoria de açio (do que as pessoas fazem), e, no entanto, quando caracterizam relevância, ela é sempre divorciada do que os participantes de um discurso estâo realmente fazendo. Clark enfatiza que S.W se limitam a falar do significado de comunicaçào, mas certamente năo do seu objetivo, quando afirmam: "O objetivo da comunicaçalo em geral ... é aumentar a mutualidade de ambientes cognitivos e talvez a similaridade de pensamentos' (S-W, 1986:39). Prossegue dizendo que as pessoas falam como um meio de fazer coisas que elas só podem fazer coletivamente larguindo, instruindo, negociando, contando históriast, o que estí de acordo com os esforços cooperativos caracterizados por Grice, ao desenvolver a noça de 'propósito comum' lou de uma direçáo mutuamente aceita), unindo os participantes de uma conversaçăo, e nâo com a noçầo de manifestabilidade mútua desenvolvida por S-W.

Qutra critica relacionada à noçào de manifestabilidade de ambientes cognitivos mûtuos na comunicaşào ê feita por Gerrig, ao levantar dificuldades em tratar fenómenos para os quais o CM tem sido invocado tradicionalmente. Para esse autor, S-W nalo consideram a importaincia do CM da identidade do falante, por exemplo, como fator de desambiguaçào de um enunciado, o que condenaria a relevância a ter pouco efeito na interpretaçắo do mesmo. Essa expectativa do limitado papel da relevància em situaçōes mutuamente conhecidas pelo comunicador e pelo destinatário é sustentada por casos de irrelevancia acidental, nos quais o destinatário já sabe com certeza de uma informaçấo (sem ambigüidade) dada pelo falante. Gerrig argúi, entăo, que um enunciado que replica informaçấo já conhecida, segundo S-W, nâo tem efeitos contextuais (nấo modifica o ambiente cognitivo) $e$, portanto, nenhuma relevalncia. Assim, a teoria da relevinincia, sem a noçào de que os falantes podem ser apenas tho relevantes quanto seu CM permite, parece predizer, contra-intuivamente, que o ouvinte seria levado a procurar outra interpretaçăo, fazendo inferèncias altamente inapropriadas, em qualquer ocasiầ em que o falante (acidentalmente) enunciasse informaçio da qual o destinatário tivesse certeza prévia. Na visāo de Cerrig o CM poderia eliminar essa dificuldade, uma vez que o enunciado seria relevante dentro do contexto definido pela informaça mutuamente conhecida.

Para responder às criticas acima, é preciso esclarecer, inicialmente, que o "propósito comum', a que se refere Clark, é uma questắo de identidade de 
interpretaçōes para que a comunicaçaio sepa bem-sucedida; de acordo com 5 W, tal identidade năo 6 garantida pelo fato de haver um mesmo objetivo da parte do falante $e$ do ouvinte, ou de ambos compartilharem um mesmo conhecimento, nem simplesmente pelo fato de um ato comunicativo estar centrado nas intençōes informativas do comunicador, segundo a modelo inferencial griceano.

O simples reconhecimento de uma intençio informativa nào garante a sua realizaçâ, como Grice tentou demonstrar. Para os autores, a comunicaçio ocorre nảo apenas quando o falante tem intençăo de informar o ouvinte de algo, mas quando tem a intencío de informar a audiència da sua intença de comunicar. A intencào comunicativa pode ser cumprida sem que a intençào informativa o seja. Por exemplo: A quer que B a convide para jantat, mas naio quer pedir-the isso abertamente. Ao passarem por um restaurante, A manifesta a sua fome inspirando prazerozamente o cheiro de comida e abre a bolsa à procurn de dinheiro, quase veladamente. Ou seja, A nào quer que staa intençào informativa se torne mutuamente conhecida de ambos e, desse modo, a intençáo comunicativa de A tem a sua intençio informativa oculta de B. Se tomarmos por base que a comunicaça é efetivada pela audiência quando esta reconhece a intençăo informativa do comunicador como propōe Grice, ou se nos basearmos na noçăo de CM, entaio o viltimo exemplo nâo 6 um caso de comunicaçalo verdadeira. Mas sabemos que a comunicaçào pode ser efetivada desse modo em nossas inferéncias diarias.

Além disso, é preciso explicitar que para S-W, comunicaçáo nado é uma questào primária, pois nầo envolve um conjunto distinto e homogêneo de fenômenos empiricos; o que os autores pretendem é "identificar os mecanismos subjacentes, enraizados na psicologia humana, que explicam como os seres humanos se comunicam uns com os outros'(1986:32). Entendendo a comunicaçio năo como um fim em si mesma, mas comum meio para um fim, o seu objetivo, entâo, năo $\mathrm{e}$ anatisar o uso da linguagem comum, nem a linguagem da comunicaçio como uma 'acăo coletiva', segundo Clark. Eles se propóem a responder, basicamente, duas questōes: o que é comunicado e como é comunicado, descrevendo explicando os processos inferenciais na compreensão verbal humana.

Para tal propósito, S-W apresentam argumentos convincentes a favor da manifestabilidade mutua de ambientes cognitisos, reafirmando que a hipótese de CM nầo é condiçào suficiente para a descriçăo explicaçấo da comunicaçào verbal. Primeiro, fornecem a noção de contexto como sendo o conjunto de premissas utilizado para interpretar enunciados, dizendo ser este um construto psicológico, um subconjunto de suposiçōes do ouvinte sobre o mundo, que afeta a interpretação do enunciado, Enfatizam que, mesmo mantida a convergência dos membros de uma comunidade com relaçào à lingua $e$ as habilidades inferenciais, dificilmente esses individuos 
compartilhariam as mesmas suposiçóes sobre o mundo. Por serem altamente idiossincráticos, cles memorizam diferentemente fatos e informaçôes básicats, interpretando-os de forma-distinta. A única maneira de impedir a má compreensào seria garantir que os contextos efetivamente utilizados pelo falante e ouvinte fossem idênticos. Mas, supondo que eles usassem apenas as informaçóes que compartilham sobre o mundo, formar-se-iam suposiçóes de primeira, segunda, terceira ordem, infinitamente, ou seja: um falante 5 e um ouvinte A conhecem mutuamente a proposiçầ $P$, se e somente se

$\begin{array}{lc}\text { I. } S \text { sabe que } P & \text { IV-A sabe (I) } \\ \text { II- A sabe que P } & \text { V- } 5 \text { sabe (IV) } \\ \text { III- } S \text { sabe (II) } & \text { VI - A sabe (III) } \\ & \\ \text { e assim por diante }(S-W / 982: 61) & \end{array}$

A questào, nesse caso, é saber que grau de conhecimento compartilhado é suficiente para a comunicaçato ter sucesso e achar um procedimento para distinguir CM de conhecimento que nào é múfuo. Talvez fosse possivel fazer isso através de uma série ilimitada de checagens, visando à restricào do $\mathrm{CM}$, mas, alèm de tomar um tempo que excederia a rapidez da produçâo e compreensia de um enunchado, nato há garantia de que tal procedimento fosse bem-sucedido. S-W dizem que, mesmo quando duas pessoas estaio olhando para uma mesma coisa, podem identificá-la diferentemente e podem náo reconhecer ou compreender os mesmos fatos. Consequentemente, se as suposicōes do CM podem ser enganosas ou inconclusivas, essal hipótese nato dáf garantias ao ouvinte de uma compreensào adequada, $e$, se o CM nâo for uma certeza, ele nâo existe, isto é, se nào sabemos que temos conhecimento mútuo de um fato ou com alguém, ențio nào o temos.

S-W apontam outro problema, ainda relativo à hipótese do C.M: embora fosse possivel definir uma classe de contextos potenciais para a interpretacaio do enunciado, nada seria dito sobre como um contexto real é selecionado, nem sobre o papel do contexto na comunicaçào. Em vista disso, afirmam que, quando um conhecimento é considerado mútuo, ê mais um resultado da compreensào do que uma pré-condiçio para ela, e apresentam como altemativa para aprimorar tal hipótese a noçào de ambiente cognitivo mútuo, no qual é manifesto que as pessoas o compartilham.

Resultante dessa idéla, entào, a noçio de manifestabilidade mútua refere-se a todas as suposicóes manifestas naquele ambiente, que deverá ser alterado para atingir a comunicaçio. Tal noçăo fundamenta o PR, segundo o qual temos um conjunto de suposicoes que se tornam manifestas ou mais manifestas em graus variados. Hà fatos que sào manifestos a um individuo, 
sem que ele tenha conhecimento ou faça suposicónes sobre os mesmos. S-W distinguem, como já foi visto na seçào anterior, manifesto, suposto e conhecido, ressaltando que ser manifesto 6 ser perceptivel ou inferivel $e$ qualquer suposiçào que alguém é capaz de construir ou aceitar como verdadeira, ou provavelmente verdadeira, 6 manifecta para ele. Mas hâ suposiçōes que sầ mais manifestas para um individuo, em funçio de seu ambiente físico e de suas habilidades cognitivas. Por exemplo, se a campainha da porta toca, é mais manifesto, segundo os autores, que há alguém na porta do que a suposiçào de que há alguém alto o suficiente para tocá-la ou de que a campainha nalo tenha sido roubada.

Um fato pode ser manifesto sem ser conhecido e suposto; para set conhecido, tem que ser verdadeiro, ao passo que pode ser manifesto e falso; por outro lado, nem tudo que é manifesto è suposto: as suposiçóes nâo precisam ser verdadeiras e podem ser derivadas de outras suposiçōes. Além disso, se algo pode ser manifesto só por ser perceptivel, entào não precisa ser inferivel do conhecimento e das suposiçôes anteriores. Exemplo disso é um carro passando audivelmente na rua; se nâo prestamos atençầ a ele, nào temos conhecimento do carro e nenhuma suposição sobre o mesmo, mas esse fato é manifecto para nós.

Desse modo, S-W mostram que manifesto e mais fraco do que conhecido ou suposto e, justamente por isso, uma noçào de manifestabilidade mûtua pode ser desenvolvida de modo mais plausivel psicologicamente, uma vez que as pessoas nado compartilham ambientes cognitivos totais nem necessariamente as mesmas suposiçôes, apenas sảo capazes de fazè-lo. Uma suposiçảo mutuamente manifesta, entâo, é sobre ambientes cognitivos e nào sobre estados ou processos mentais, E 6 forte o suficiente para dar conta da comunicaçăo, que é um processo aberto, assimétrico, governado por uma heuristica menos que perfeita, nào exigindo uma coondenaçầ simétrici entre comunicador e audiência na escolha de código e contexto.

Quanto ao posicionamento de Gerrig, ao evocar o CM para resolver dificuldades na comunicaçào, o seu argumento é o papel limitado da relevância nas questôes de desambiguaçāo de enunciados em situaçōes mutuamente conhecidas pelo falante e ouvinte, e nos casos de irrelevância acidental, quando o comunicador reporta informaçào velha ou replicada. Entretanto, o que o autor salienta como uma condicâo necessária e suficiente para CM é simplesmente um ambiente cognitivo mútuo. Do mesmo modo, os exemplos que apresenta nầo sào de CM, mas de manifestabilidade mútua. Ele retoma o enunciado 'Jennifer admitiu roubar', apresentado por S-W, afirmando que, para um destinatário que conhece duas 'Jennifer, a atribuiçâo do referente, através do CM do comunicador e do ouvinte, permitiria a interpretação correta: se a sentença fosse enunciada pelo marido de lennifer, por exemplo, o ouvinte náo teria dúvidas em saber a qual das duas o 
comunicador estava se referindo.

A importância do CM da identidade do falante, defendida por Gerrig como fator de desambiguaça de um enunciado, é refutada por S-W. Eles entendem que o individuo faz parte do contexto e do ambiente mutuamente manifesto, e é isso que possibilita, de modo mais plausivel e mais fácil, a atribuiçào do referente. Certamente Gerrig nâo leva em conta que o comportamento ostensivo fornece evidência dos pensamentos de alguém porque implica uma garantia de relevåncia, que torna manifesta a intencaio por trás da ostencio: em outras palavras, o PR. E tampouco considera que todos os enunciados têm uma primeira interpretaçào consistente com o PR. que é suficiente por si próprio para dar conta da interação de significados lingǘsticos com fatores contextuais na desambiguaçāo, na atribuiçăo do referente, na resoluçào de indeterminâncias, bem como na recuperaçio das implicaturas na compreensalo verbal.

O autor também se equivoca, ao abordar casos de irrelevância acidental para tratar de informaçào velha já conhecida,confundindo um critério de consistència com a presunçaio, antes do que com o principio, de relevância ótima. S-W enfatizam que, quando nenhum nivel satisfatório de relevància é alcancado, uma suposiçåo plausivel é que o comunicador tentou ser otimamente relevante, mas fracassou. Por exemplo, se um falante expressa uma proposiçato P pretendendo informar o ouvinte de P, sem saber que ele já tinha essa informaçao, embora P seja irrelevante para o ouvinte e. consequentemente, inconsistente com a presunçio de relevância, o enunciado do falante é consistente com o PR. O enunciado teria, entấo, sido apropriado e, além disso, o risco teria sido razoável devido à expectativa do falante em ser bem-sucedido.

Desse modo, para S-W é suficiente que a presunçấo de relevåncia deva ser comunicada; năo tem que ser aceita como verdade para desempenhar o seu papel mais importante: determinar a interpretaçáo do estimulo ostensivo. Estímulos ostensivos provocam expectativas definidas de relevăncia, que é alcançada se a intençâo informativa do comunicador é reconhecida.

Cremos ter justificado os pressupostos da releváncia de S-W aqui discutidos e ter demonstrado que as criticas de Clark e Gerrig săo passiveis de forte contra-argumentaça a favor do quadro teórico dos autores, particularmente do PR relacionado as noçóes de manifestabilidade mútua e ambiente cognitivo.

\section{4- Conclusổes}

Retomando as discussóes da seçào anterior, alguns aspectos merecem ser reafirmado5. Entre eles, 05 argumentos comvincentes de $5-W$ favoráiveis à noçào de manifestabilidade mútua, potencial, que, exatamente por ser mais fraca e ter um menor grau de exigência do que a hipótese do CM, é mais adequada à compreensào humana. Tal adequaçào se justifica pelo fato de 
que, em nossas inferềncias diânas, nas situaçốes comunicativas, nào checamos e analisamos todas as proposiçôes para verificar o conhecimento comum, condicăo necessária para que o $\mathrm{CM}$ desempenhe um papel na compreensióo do enunciado.

O argumento formal de que o CM é necessário, como defendem Clark e Gerrig, aplica-se apenas à compreensấo perfeita na comunicaçào e nấo a forma imperfeita, reconhecida como suficiente no dia-a-dia (S-W,1982:69). Enquanto podemos construir muitas descriçoes e suposiçōes do mesmo estímulo físico, a compreensăo adequada implica identidade ou similaridade de interpretaçóes entre os interlocutores. Além disso, o CM não é suficiente para que uma proposiçăo pertença ao contexto; ela pode ser mutuamente conhecida sem ser parte dele; do mesmo modo, uma suposiçào pode pertencer ao contexto sem ser mutuamente conhecida. Nầo é, assim, uma questầo de propósito comum, como supōe Clark, ou de conhecimento mütuo, conforme Gerrig. nem tampouco de duplicaçio de pensamentos, mas sim uma questăo de identidade de interpretaçoes que possibilitară que a compreensào humana se efetrve com sucesso.

Comunicar, segundo S-W, é requisitar a atençâo de alguém, através de um estímulo ostensivo; conseqüentemente, comunicar é implicar que a informação comunicada 6 relevante, o que garante a presunçio de relevância ótima. Se, por um lado, o PR, através de um estimulo ostensivo, torna mutuamente manifesto que a realizaçăo da intenção informativa está nas "mâos' da audiéncia, entào os interesses do comunicador e do ouvinte șío levados em conta para a presunçào de relevància ótima. Esta fornecerá um critério suficiente para selecionar, de um conjunto de suposiçōes, uma interpretaçio consistente com o PR.

Se, por outro lado, o PR, ao se aplicar, modifica e estende o ambiente cognitivo mútuo que os seres humanos compartilham entre si, entaio os efeitos contextuais de uma informação sâo considerados. Os efeitos contextuais necessários para alterar o ambiente cognitivo do ouvinte sấo obtidos por processos mentais; estes, como os procescos biológicos, envolvem um certo esforco. Assim, tal esforço de processamento somado aos efeitos contextuais sâo os dois fatores que permitirâo o conceito comparativo de relevância.

Para finalizar, deve ser salientado o mérito de S.W especialmente em dois pontos; um deles é a denúncia que fazem ao compromisso da informaçấo precisa dos modelos mais clássicos da comunicaçào e o outro, decorrente do primeiro, é que tratam a vaguidade, enquanto objeto, como um fenòmeno objetivo da comunicaçio dentro de uma teoria rigorosa e precisa, com enf́oque cognitivista. A sua tese é a de que a comunicaçáo nảo deve ser modelada pelo quadro das trocas de informaçòes precisas através do modelo de código, que pressupóe que a comunicaçâo seja efetivada pela codificaçăo e decodificaça de mensagens. Segundo os autores de Relevance, queremos 
compartilhar com os outros o que sabemos e o que nåo sabemos, as nossas impressôes, crenças, dôvidas, etc, Isso implica que a vaguidade também faz parte da comunicagăo, e que é necessaino dizer coisats precisas sobre ela, sem confundir o nivel da teoria com o do objeto.

Sem duvida, ainda muitos estudos abordando os processos da compreensăo humana se fazem necessários, mas certamente eles não enfraquecerâo o modelo de comunicaço ostensiva-inferencial dos autores; a expectativa é a de um fortalecimento do quadro teórico desenvolvido por 5 . W, centrado na relevância

\section{Referências bibliográficas}

1. AUSTIN,JL. (1962) Haw to do Things with Words. Oxdord, Clarendon.

2. ClaRK,H,(1987) "Relevance to what? Behavioral and Brain Sciences. Cambendge, Cambridge University Press, 10:4

3. FODORIAUga3) The modularity of mind Mil Press, Cambridge. Massaschusetts

4- GERRIG,RI (1907) " Relevarice theory, mutual knowledge and acodental irrelevance Behavioral and Brain Sciences. Cambridge, Cambridge Univeralty Press

5. GRICE.HP(975y Lopic and Conversation' In Cole \& Morganieds Sintax and Semantics Voll 7 Speech Acts. New York, Acadersic Press

6- SPERBER. D \& WILSON,D (T982) Mutual Knowledoe and Rolrvance in theories of Comprehension in SMITH fed) Mutual Knowledge New Vork, Academic Press: $\mid p \cdot 61-85$ )

7. _- $(1966)$ Relevance: Communication and Cognition. Harvard Liniversily Press, Cambindge, Masuastusetts

8- no91) Loowe Talk In: Davis led. I Pragmatics - A. Reader. New Work, Oxiond University Press

9. WILSON,D \& SPFRBTR,D (1906) "Inference and Implicature In. Iravis/ed) Meaning and Interpretation. Oxiotd, Elasil Biackwell. 